\title{
An Overview of Management of Early-onset Scoliosis
}

\author{
${ }^{1}$ Sashin Ahuja, ${ }^{2}$ Omar A Ibrahim
}

\begin{abstract}
Management of early-onset scoliosis (EOS) is a challenging dilemma. EOS is usually defined as a curve more than $10^{\circ}$ in a child below the age of 10 years. The main issues to take into account for a child with EOS are a curve progression and growth of the spine and the thoracic cage to allow normal development of the lungs. There are various options available to manage an EOS progressive curve which could range from bracing to surgical intervention. All these options have certain advantages and pitfalls which should be taken into consideration in formulating a management plan for these young children.
\end{abstract}

Keywords: Early-onset scoliosis, Growing rods, Surgery.

How to cite this article: Ahuja S, Ibrahim OA. An Overview of Management of Early-onset Scoliosis. J Postgrad Med Edu Res 2017;51(2):84-88.

Source of support: Nil

Conflict of interest: None

\section{INTRODUCTION}

The cause and prevention of scoliosis has and still eludes us. Early-onset scoliosis (EOS) is defined as a curve more than $10^{\circ}$ in a child below the age of 10 year. This concept was described by Dickson. ${ }^{1}$ A progressive EOS curve is not only a cosmetic problem but it can affect the cardiopulmonary function. The bronchial tree, i.e., the alveoli develop mainly between birth and 8 years of age. The thoracic volume is approximately $50 \%$ by the age of 10 years., ${ }^{2,3}$ Therefore, treatment should be guided toward the preservation of growth rather than fusion surgery at an early stage.

Fusion surgery at an early stage for this spinal deformity is no longer an option. The main aim is to control the spinal deformity and allow growth of the spine and the thoracic cage allowing normal lung development. The spine grows most rapidly in the first 5 years, with an average T1 to S1 segment length increase of $10 \mathrm{~cm}$ during this time $(2 \mathrm{~cm} / \text { year })^{2,3}$

The number of alveoli and lung volume increase rapidly in the first several years and continue to increase at a lower rate during adolescence and adulthood..$^{2-4}$

\footnotetext{
${ }^{1}$ Consultant, ${ }^{2}$ Senior Spinal Fellow

${ }^{1,2}$ Department of Orthopedics, University Hospital of Wales Cardiff, Wales, United Kingdom
}

Corresponding Author: Sashin Ahuja, Consultant, Department of Orthopedics, University Hospital of Wales, Cardiff, Wales United Kingdom, Phone: +2920715111, e-mail: sashinahuja@ gmail.com
Lung function studies of children with EOS demonstrate a variable severity of restrictive lung disease caused by small lung volumes, reduced chest wall compliance, and respiratory muscle dysfunction. ${ }^{5}$

These children can suffer with thoracic insufficiency syndrome (TIS) which is the inability of the thorax to support normal respiratory function and lung development in growing children. This term has been popularized by Campbell et al. ${ }^{6}$ The TIS patients have a poorer quality of life scores than those of patients with epilepsy, heart disease, and cancer. ${ }^{7}$

Treatment for EOS is a challenge for spinal surgeons as these children often need multiple procedures. These children often have associated comorbidities which would need to be managed through the treatment journey and beyond.

\section{WHAT CAUSES EOS?}

There are various causes for the development of EOS but the common causes to describe a few are as follows:

\section{Idiopathic}

The incidence of idiopathic scoliosis has been reported to be about $1.5 \%{ }^{8}$ Those are the curves for which no specific cause could be identified. The children in this group are generally healthier and do not have any significant comorbidities.

\section{Congenital}

This includes a congenital abnormality of the structure of the spine. This could either be due to failure of formation (e.g., hemivertebra), failure of segmentation (e.g., unsegmented bar) or a combination of the two. One should also consider other system anomalies in this group. This may include cardiac and renal anomalies (VACTERL syndrome). Other musculoskeletal anomalies may also be involved. What is peculiar about the management of this group is that early short spinal segment fusion may be the exception to growth preserving spine surgery performed for EOS.

\section{Neuromuscular}

Cerebral palsy, muscular dystrophies, and myopathies cause abnormalities in muscular tone. This leads to scoliosis. Curves in this group are long sweeping C-shaped curves. 


\section{Syndromic}

Various syndromes, e.g., Marfans, Ehlers-Danlos, and other connective tissue disorders, as well as neurofibromatosis, Prader-Willi, and many bone dysplasias may be associated with EOS.

\section{TREATMENT STRATEGIES}

The main principles for management of the scoliosis would be:

- Avoid or delay spinal fusion as much as possible

- Allow for lung and chest wall development

- Control or halt the spinal deformity

- Consider overall impact on the family

- Management of the underlying condition and the associated comorbidities.

\section{MANAGEMENT OPTIONS}

\section{Casting/Bracing}

Low-magnitude curves may be addressed by bracing. Its efficacy, however, is questionable. Bracing is ineffective, especially in congenital curves. This is also true for those EOS patients with high risk of progression based on the ribvertebral angle difference of $>20^{\circ}$ as described by Mehta. ${ }^{9}$ Bracing is not devoid of complications and requires a cooperative compliant child with prolonged use and regular changes to accommodate truncal growth. Parent's compliance is also another issue to consider.

There has been a resurgence of casting in the management of EOS. ${ }^{10}$ It is a safe, cheap method, and above all it avoids the complications of surgery. Furthermore, it can delay fusion surgery. Mehta demonstrated that casting may be effective in completely resolving some curves, especially those of lower magnitude. ${ }^{11}$ Under anesthesia and with traction, the cast is applied and molded while attempting derotation and correcting the deformity. The casts need to be changed every 8 to 10 weeks approximately and this may help maintain the correction and prevent further deformity. ${ }^{11}$ Usually, casting is an option for low-magnitude curves which show minimal progression. It may also be used as a "time buying" tool to delay surgery especially in very young children.

\section{SURGERY}

The dilemma faced by the surgeon is how to stop the progression of a curve without adversely affecting spine/trunk growth. Surgery is usually performed if conservative measures mainly bracing fail to control the curve progression and we then have to resort to surgical techniques to manage the deformity.

In the past fusion surgery, e.g., epiphysiodesis surgery used to be performed. But the general trend in the recent past is to move away from fusion surgery which is the last resort for young patients with aggressive EOS curves. Furthermore, fusion surgery for the young may still fail despite circumferential fusion of the spine due to continued growth. The crankshaft phenomenon is welldescribed by Dubousset ${ }^{12}$ as persistent anterior growth of the vertebral bodies in presence of posterior fusion. Therefore, there was need to develop fusionless surgery.

\section{Fusionless Surgery}

This technique allows correcting and controlling the spinal deformity and at the same time allowing growth and development of the thoracic cage and lungs. With advances in technology, there has been development of "growth friendly spinal implants" (GFSI).

The GFSI may be divided according to the forces they exert on the spine into distraction-based and compression based. ${ }^{13}$ There are other systems available as well which rely on growth guidance.

\section{Distraction-based Growing Rods}

Growing rods are an example of distraction-based GFSI. The procedure of implanting these rods involves proximal and distal anchoring foundations using pedicle screws or hooks. Rods are inserted in a submuscular fashion without exposing the rest of the spine and connected to the proximal and distal foundation thereby correcting the curve. The rods can then be lengthened at regular intervals to allow the spine to grow until definitive fusion is indicated.

This form of procedure could be performed either using single rod on the side of the concavity or bilateral dual growth rods. The pediatric isola dual rod instrumentation is one technique of dual growth rod developed by Akbarnia et al. ${ }^{14}$ (Fig. 1). Akbarnia has reported the results of a multicenter study of 23 patients with 2-year follow-up. Initial surgery was at 5 years and 5 months of age with an average of 6.6 lengthenings. Curve magnitude decreased from 82 to $38^{\circ}$ at initial surgery with no significant loss of correction over time. ${ }^{15}$ Moreover, Akbarnia et al also demonstrated that patients whose spines were lengthened at $\leq 6$-month intervals had significantly higher annual T1 to $\mathrm{S} 1$ growth rate of $1.8 \mathrm{~cm} /$ year, compared with $1.0 \mathrm{~cm} /$ year in patients whose spines were lengthened less frequently. ${ }^{16}$

This, however, is not free from complications. Repeated surgical distraction every 6 months potentially increases the risk of infection. Those patients often have small and thin body habitus and the implants are relatively large resulting in implant prominence and poor soft tissue coverage. ${ }^{17}$

With the technique used for the proximal and distal foundation by using pedicle screws, there usually is 


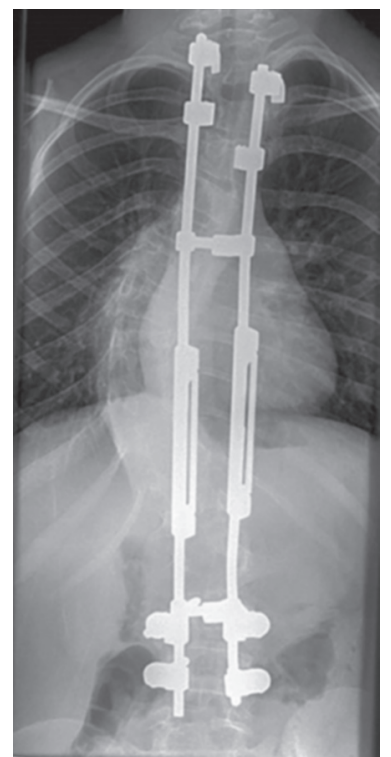

Fig. 1: Dual growth rods, i.e. pediatric isola construct

autofusion of the anchoring foundation mainly due to the subperiosteal dissection to implant the screws. Hence, the rod is inserted submuscularly to avoid the risk of autofusion and at the same time have adequate soft tissue cover over the implants.

There are some concerns with the use of rigid proximal implants, i.e., pedicle screws due to possible risk of failure. Hence some surgeons prefer to use a hybrid construct, i.e., use hooks as anchors for proximal foundation. This permits some motion of the implant hence avoid stress risers and failure. These could be as sublaminar hooks or attached to the rib making the construct less rigid. ${ }^{17}$ Proximal rib-anchored growing rods showed less breakage than spine-anchored rods in some studies as demonstrated by Yamaguchi et al. ${ }^{17}$ However, other published series have shown that no correlation was found between patient weight or type of implant (screw or hook). ${ }^{18}$ These issues would be worth considering when planning anchorage and aiming to distribute anchorage stress by perhaps using a combination of screws and hooks depending on the various factors, i.e., scoliosis curve, associated kyphosis, bony anatomy, etc.

\section{Magnetically Controlled Growing Rod (MCGR)}

The MCGR are types of growing rods which are implanted in a similar fashion as described above. ${ }^{19,20}$ But it utilises a magnet in the telescoping portion of the rod. The main advantage of system is that it avoids the need for surgical lengthening of the rods under general anesthetic every 6 months, and hence minimizes surgical complications. These rods can be lengthened as outpatient procedure using an external remote controller to distract the magnetically controlled growing rod system (Fig. 2).

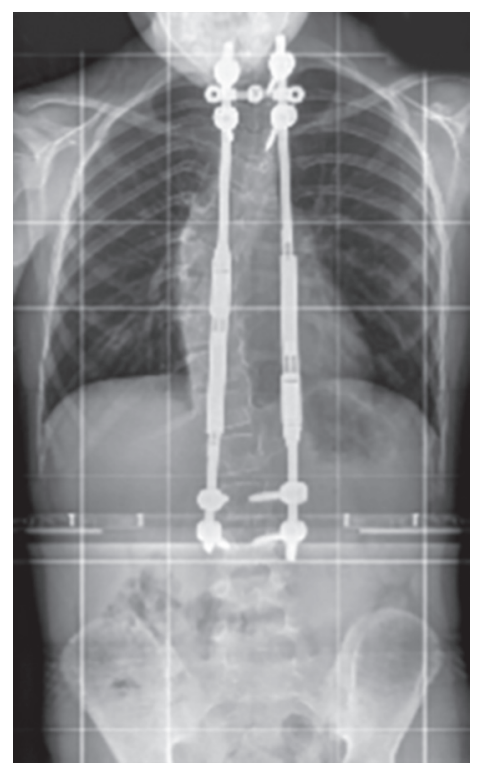

Fig. 2: Magnetically controlled growth rod

Akbarina et al have demonstrated that major curve correction was similar between MCGR and traditional growing rods patients throughout treatment. Annual T1S1 and T1-12 growth was also similar between groups. The MCGR patients had 57 fewer surgical procedures. ${ }^{21}$

Unfortunately, convenience from technology and noninvasive distraction system is not devoid of complications. A study from our center comparing MCGR to conventional growth rods showed that MCGR has a lower rate of both deep and superficial infections when compared with conventional rods. However, it does not completely avoid further surgical procedures as previously postulated. Metalwork complications and unplanned return to theater was still significant. ${ }^{22} \mathrm{~A}$ further study from our center has recently demonstrated evidence of metallosis around the MCGR in 4 out of 5 patients requiring revision surgery and based on our retrieval analysis we have postulated a mechanism for the metallosis. ${ }^{23}$

\section{Vertical Expandable Prosthetic Titanium Rib (VEPTR ${ }^{\circledR}$ )}

Originally described by Campbell as expansion thoracoplasty for TIS in 2003. ${ }^{5}$ The vertical expandable prosthetic titanium rib $\left(\mathrm{VEPTR}^{\circledR}\right.$ ) offers control of the thoracic component of spinal deformity. However, the spine and thorax are closely linked. The VEPTR ${ }^{\circledR}$ also requires repeated surgical distraction at 6 monthly intervals. The anchorage sites here are however different. The VEPTR ${ }^{\circledR}$ can be anchored onto the ribs proximally and distally to the ribs, spine or pelvis (Fig. 3).

The VEPTR ${ }^{\circledR}$ has been used mainly for patients with TIS due to abnormality of the rib cage which prevents normal development of the lung due to the lack of space available for the lung. It is performed in cases where 


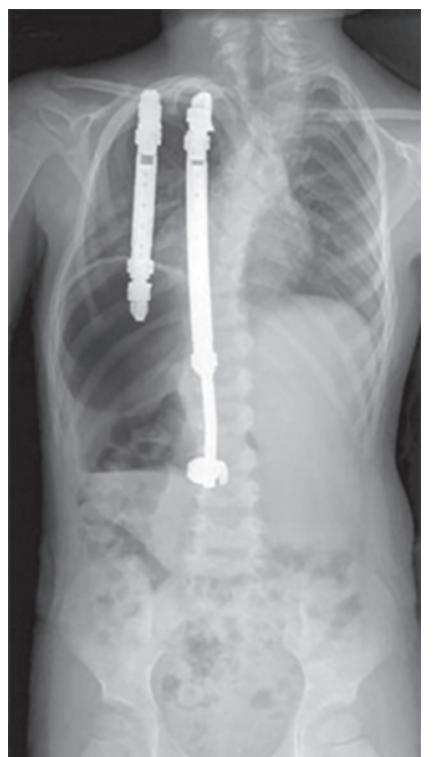

Fig. 3: Vertical expandable prosthetic titanium rib—rib to rib and rib to spine constructs

casting/bracing are not appropriate. The VEPTR's spinesparing approach might provoke less spontaneous spinal fusion and ease the final correction at maturity. ${ }^{24,25}$

\section{COMPRESSION-BASED DEVICES}

\section{Spinal Tethering/Stapling}

In this technique, either a staple ${ }^{26}$ or a flexible nonfusion device is used as a tether on the convexity of the curve. $^{27}$ Stapling or anterior vertebral body tethers act as an internal brace and the procedure can be carried out thoracoscopically.

This concept is similar to convex epiphysiodesis but does not involve fusion of the convexity and is fusionless. It works on the Heuter-Volkmann biomechanical concept by causing compression on the convexity of the curve thereby slowing down the growth. The aim is to preserve spinal growth, motion and function, and the avoidance of adjacent segment degeneration above or below fused segments, however long-term data is not yet available. Most of the studies involving these procedures are performed for adolescent idiopathic scoliosis to prevent full correction and fusion of the curve.

\section{GROWTH GUIDANCE}

Another option for surgical management of EOS is growth guidance whereby spinal growth force is utilized to lengthen the assembly. One of the oldest techniques described is the Luqué trolley whereby $2 \mathrm{U}$ (or L-shaped) shaped rods anchored segmentally to the spine with sublaminar wires. The rods overlap in the middle segment which allows the rods to glide with spinal growth that allows the spine to grow and the same time maintain the

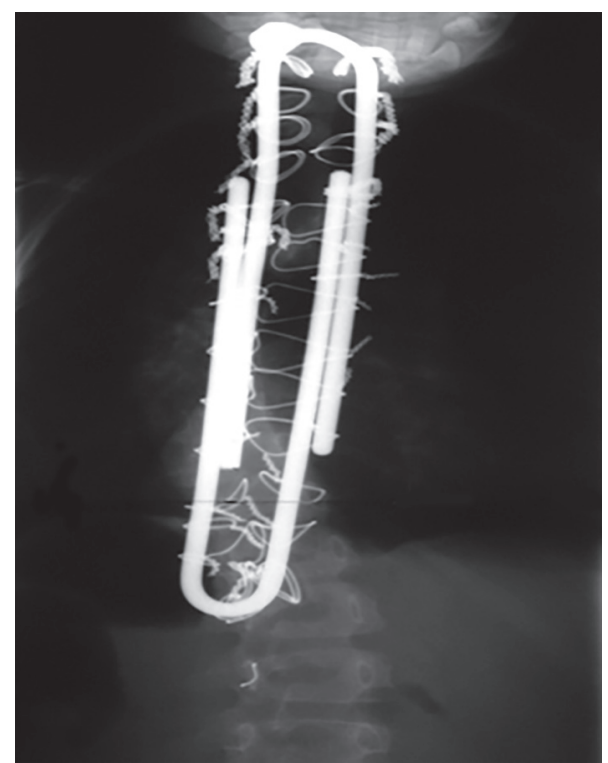

Fig. 4: Luqué trolley, i.e. two U-shaped rods anchored using sublaminar wires

curve correction of the spine. ${ }^{28-30}$ (Fig. 4). But there have been reported complication of this technique, i.e., fusion across the spine (which needed to be exposed for implantation of the sublaminar wires) and wire/rod breakage, etc. ${ }^{30}$ This technique has been modified to a modern version of the Luqué trolley, i.e., using proximal and distal anchors like the growing rods using pedicle screws and using overlapping rods anchored with sublaminar wires in the middle of the curve to correct the curve and allow growth of the spine due to self gliding of the rods like the original Luqué trolley concept. ${ }^{31}$

Another growth guidance option for EOS is the Shilla technique $^{32}$ In this technique, an apical short segment fusion is performed. The spine is stabilized proximally and distally with nonlocking polyaxial screws to guide a rod, i.e., purposefully left long to minimize the need for subsequent surgery. As spinal growth occurs, the rod slides through the nonlocking screws. ${ }^{32,33}$

\section{CONCLUSION}

The treatment for EOS with a progressive spinal curve is extremely challenging taking into consideration the various anatomical and physiological aspects of development to go with it. We do have various nonoperative and operative options at our disposal. But these modalities have their own pitfalls and complications. As far as possible, one would prefer to treat an EOS curve nonoperatively with a brace. Multidisciplinary coordination is often required and beneficial for this subset of patients. But if surgery becomes necessary, one needs to counsel the family about the treatment journey and potential problems which we may have to come up against till a definitive fusion and correction can be performed when the child is in the adolescent age group. 


\section{REFERENCES}

1. Dickson RA. Early-onset idiopahic scoliosis. In: Weinstein S, editor. The pediatric spine: principles and practice. New York, NY: Raven Press; 1994. p. 421-429.

2. Dimeglio A, Canavese F. The growing spine: how spinal deformities influence normal spine and thoracic cage growth. Eur Spine J 2012 Jan;21(1):64-70.

3. Canavese F, Dimeglio A. Normal and abnormal spine and thoracic cage development. World J Orthop 2013 Oct;4(4): 167-174.

4. Thurlbeck WM. Postnatal human lung growth. Thorax 1982 Aug;37(8):564-571.

5. Vitale MG, Matsumoto H, Roye DP Jr, Gomez JA, Betz RR, Emans JB, Skaggs DL, Smith JT, Song KM, Campbell RM J. Health-related quality of life in children with thoracic insufficiency syndrome. J Pediatr Orthop 2008 Mar;28(2):239-243.

6. Campbell RM Jr, Smith MD, Mayes TC, Mangos JA, Willey-Courand DB, Kose N, Pinero RF, Alder ME, Duong HL, Surber JL. The characteristics of thoracic insufficiency syndrome associated with fused ribs and congenital scoliosis. J Bone Joint Surg Am 2003 Mar;85-A(3):399-408.

7. McMaster MJ. Infantile idiopathic scoliosis: can it be prevented? J Bone Joint Surg Br 1983 Nov;65(5):612-617.

8. Mehta MH. The rib-vertebra angle in the early diagnosis between resolving and progressive infantile scoliosis. J Bone Joint Surg Br 1972 May;54(2):230-243.

9. Mehta MH. Growth as a corrective force in the early treatment of progressive infantile scoliosis. J Bone Joint Surg Br 2005 Sep;87(9):1237-1247.

10. Demirkiran HG, Bekmez S, Celilov R, Ayvaz M, Dede O, Yazici M. Serial derotational casting in congenital scoliosis as a time-buying strategy. J Pediatr Orthop 2015 Jan;35(1):43-49.

11. Baulesh DM, Huh J, Judkins T, Garg S, Miller NH, Erickson MA. The role of serial casting in early-onset scoliosis (EOS). J Pediatr Orthop 2012 Oct-Nov;32(7):658-663.

12. Dubousset J, Herring JA, Shufflebarger H. The crankshaft phenomenon. J Pediatr Orthop 1989 Sep-Oct;9(5):541-550.

13. Skaggs DL, Akbarnia BA, Flynn JM, Myung KS, Sponseller PD, Vitale MG; Chest Wall and Spine Deformity Study Group; Growing Spine Study Group; Pediatric Orthopaedic Society of North America; Scoliosis Research Society Growing Spine Study Committee. A classification of growth friendly spine implants. J Pediatr Orthop 2014 Apr-May;34(3):260-274.

14 Akbarnia BA, Marks DS, Boachie-Adjei O, Thompson AG, Asher MA. Dual growing rod technique for the treatment of progressive early-onset scoliosis: a multicenter study. Spine (Phila Pa 1976) 2005 Sep;30(17 Suppl):46-57.

15. Akbarnia BA, Breakwell LM, Marks DS, McCarthy RE, Thompson AG, Canale SK, Kostial PN, Tambe A, Asher MA Growing Spine Study Group. Dual growing rod technique followed for three to eleven years until final fusion: the effect of frequency of lengthening. Spine (Phila Pa 1976) 2008 Apr;33(9):984-990.

16. Akbarnia BA, Emans JB. Complications of growth-sparing surgery in early onset scoliosis. Spine (Phila Pa 1976) 2010 Dec;35(25):2193-2204.

17. Yamaguchi KT Jr, Skaggs DL, Mansour S, Myung KS, Yazici M, Johnston C, Thompson G, Sponseller P, Akbarnia BA, Vitale $M G$, et al. Are rib versus spine anchors protective against breakage of growing rods? Spine Deform 2014 Nov;2(6): 489-492.
18. Skaggs KF, Brasher AE, Johnston CE, Purvis JM, Smith JT, Myung KS, Skaggs DL. Upper thoracic pedicle screw loss of fixation causing spinal cord injury: a review of the literature and multicenter case series.J Pediatr Orthop 2013 Jan;33(1): 75-79.

19. Dannawi Z, Altaf F, Harshavardhana NS, El Sebaie H, Noordeen $\mathrm{H}$. Early results of a remotely-operated magnetic growth rod in early-onset scoliosis. Bone Joint J 2013 Jan; 95-B(1):75-80.

20. Akbarnia BA, Cheung K, Noordeen H, Elsebaie H, Yazici M, Dannawi Z, Kabirian N. Next generation of growth-sparing techniques: preliminary clinical results of a magnetically controlled growing rod in 14 patients with early-onset scoliosis. Spine (Phila Pa 1976) 2013 Apr;38(8):665-670.

21. Akbarnia BA, Pawelek JB, Cheung KM, Demirkiran G, Elsebaie H, Emans JB, Johnston CE, Mundis GM, Noordeen H, Skaggs DL, et al. Traditional growing rods versus magnetically controlled growing rods for the surgical treatment of earlyonset scoliosis: a case-matched 2-year study. Spine Deform 2014 Nov;2(6):493-497.

22. Teoh KH, Winson DMG, James SH, Jones A, Howes J, Davies PR, Ahuja S. Do magnetic growing rods have lower complication rates compared with conventional growing rods? Spine J 2016 Apr;( Suppl 4):S40-S44.

23. Teoh KH, Von Ruhland C, Evans SL, James SH, Jones A, Howes J, Davies PR, Ahuja S. Metallosis following implantation of magnetically controlled growing rods in the treatment of scoliosis: a case series. Bone Joint J 2016 Dec;98-B(12):1662-1667.

24. Schulz JF, Smith J, Cahill PJ, Fine A, Samdani AF. The role of the vertical expandable titanium rib in the treatment of infantile idiopathic scoliosis: early results from a single institution. J Pediatr Orthop 2010 Oct-Nov;30(7):659-663.

25. Hasler CC, Mehrkens A, Hefti F. Efficacy and safety of VEPTR instrumentation for progressive spine deformities in young children without rib fusions. Eur Spine J 2010 Mar;19(3): 400-408.

26. Betz RR, Kim J, D'Andrea LP, Mulcahey MJ, Balsara RK, Clements DH. An innovative technique of vertebral body stapling for the treatment of patients with adolescent idiopathic scoliosis: a feasibility, safety, and utility study. Spine (Phila Pa 1976) 2003 Oct;28(20):S255-265.

27. Samdani AF, Ames RJ, Kimball JS, Pahys JM, Grewal H, Palletier GJ, Betz RR. Anterior vertebral body tethering for idiopathic scolisios: two-year results. Spine (Phila Pa 1976) 2014 Sep;39(20):1688-1693.

28. Luqué ER, Cardoso A. Treatment of scoliosis without arthrodesis or external support, preliminary report. Orthop Trans 1977;1:37-38.

29. Luqué ER. Paralytic scoliosis in growing children. Clin Orthop Relat Res 1982;163:202-209.

30. Mardjetko SM, Hammerberg KW, Lubicky JP, Fister JS. The Luqué trolley revisited. Review of nine cases requiring revision. Spine (Phila Pa 1976) 1992 May;17(5):582-589.

31. Ouellet J. Surgical technique: modern Luqué trolley, a self-growing rod technique. Clin Orthop Relat Res 2011 May;469(5):1356-1367.

32. McCarthy RE, Luhmann S, Lenke L, McCullough FL. The Shilla growth guidance technique for early-onset spinal deformities at 2 year follow-up: a prelimanry report. J Pediatr Orthop 2014 Jan;34(1) :1-7.

33. McCarthy RE, McCullough FL. Shilla growth guidance for early-onset scoliosis:results after a minimum of five years of follow-up. J Bone Joint Surg Am 2015 Oct;97(19):1578-1584. 